\title{
MIGUEL TORGA E SUA GEOGRAFIA NATIVA: PAISAGENS INSCRITAS
}

\section{MIGUEL TORGA AND HIS NATIVE GEOGRAPHY: INSCRIBED LANDSCAPES}

\author{
Ida Alves ${ }^{1}$ \\ ORCID: https://orcid.org/0000-0002-6892-7289
}

Cada qual procura-se onde se sente perdido. Eu perdi-me em Portugal, e procuro-me nele.

(Miguel Torga, Diário, 24/10/1958, 2001, p. 814)

\begin{abstract}
Resumo: A obra de Miguel Torga (1907-1995) é de reconhecida importância no contexto da literatura portuguesa do século XX. Disso são provas a recepção do Prêmio Camões em 1989 e a já extensa fortuna crítica publicada em Portugal e no Brasil. Um dos temas recorrentes nesses trabalhos críticos é a relação do escritor com a terra, a força telúrica tanto em sua prosa como na poesia. Neste artigo, trataremos das paisagens inscritas em sua escrita a partir do Diário de Miguel Torga (vols. I a VIII, de 1934 a 1959). Em muitas de suas anotações, o escritor demonstra a importância da geografia transmontana para configuração de sua escrita literária, sobretudo sua terra natal, S. Martinho de Anta (Concelho de Sabrosa) e espaços próximos. Na relação de Torga com essa paisagem, poderemos examinar determinadas linhas de compreensão de sua obra literária humanista e ética. Não à toa, em seu pseudônimo autoral, destaca-se "torga", vegetação de montanha que se agarra às rochas, com suas raízes fortes e caule retilíneo, assim como sua escrita profundamente ligada à paisagem rural transmontana, agreste e rigorosa, mas profundamente sensível ao humano em sua miséria ou grandeza.
\end{abstract}

Palavras-chave: Diários de Miguel Torga. Estudos de paisagem. Literatura portuguesa. Prosa literária moderna.

Abstract: Miguel Torga's work (1907-1995) is of recognized importance in the context of 20th century Portuguese literature. This is evidenced by the reception of the Camões Prize in 1989 and the already extensive critical fortune published in Portugal and Brazil. One of the recurring themes in these critical works is the writer's relationship with the land, the telluric force in both his prose and poetry. In this article, we will deal with this relationship from the Diary of Miguel Torga (vols. I to VIII), from 1934 to 1959.In many of his notes, the writer demonstrates the importance of Trásos-Montes geography for the configuration of his literary writing, especially his native land, S. Martinho de Anta (Sabrosa Municipality) and nearby spaces. In Torga's relationship with this

\footnotetext{
1 Ida Alves é professora titular de Literatura Portuguesa, Instituto de Letras da Universidade Federal Fluminense. É docente do Programa de Pós-Graduação em Estudos de Literatura UFF. Pesquisadora do CNPq e Cientista do Nosso Estado - FAPERJ (2018 -2021). Colidera o grupo de pesquisa UFF / CNPq Estudos de Paisagem nas Literaturas de Língua Portuguesa.
} 
landscape, we will be able to examine certain lines of understanding of his humanist and solidary literary work. Not for nothing, in its authorial pseudonym, "torga" stands out, mountain vegetation that clings to the rocks, with its strong roots and straight stem, as well as its writing deeply linked to the rural, rigorous and ethical landscape, harsh many times, but deeply sensitive to the human in his misery or greatness.

Key-words: Miguel Torga's diaries. Landscape studies. Portuguese literature. Modern literary prose.

Em janeiro de 2020, foi publicada pela editora D. Quixote, Lisboa, com organização e esclarecedora introdução de Carlos Mendes de $\mathrm{Sousa}^{2}$, a correspondência inédita que foi dirigida a Miguel Torga por diversas e destacadas figuras da cultura portuguesa, demonstrando-se com essa conversação epistolar o seu lugar independente de pensamento e ação. Entre as cartas, vale citar uma de Vitorino Nemésio, o qual, ao escrever sobre Bichos, afirmou: "É um lindo livro que nasce cheio da terra das suas unhas” (apud Sousa, 2020, p.12).

Dessa ligação íntima com a terra de origem, faz-se a história do pseudônimo ${ }^{3}$ Miguel Torga. É revelador desde sempre que o escritor tenha adotado como sobrenome, nome portanto que indicaria uma genealogia, a designação de uma planta brava da montanha - urze (Erica Lusitânica ${ }^{4}$ ) - denominada pelos habitantes do norte de Portugal de "torga", com raízes profundas entre as rochas, resistente às condições difíceis da natureza transmontana, especialmente na zona do planalto da Serra da Azinheira. Sabemos também que exerceu a medicina em Coimbra (concluiu o curso em 1933), onde está sua casamemória (inaugurada em 12/08/2007), mas foi sempre à pequena vila natal que retornou para encontrar os pais e suas raízes. Sua obra literária evidencia essa relação telúrica que dá sentido à sua escrita e à sua existência como homem e como criador.

Escritor múltiplo (poeta, ficcionista, dramaturgo, memorialista), primeiro Prêmio Camões (1989), é de justiça ter sempre presente sua obra que primou pela atenção ao homem

2 Professor da Universidade do Minho, Estudos Portugueses e Lusófonos, especialmente literatura brasileira. 3“O pseudónimo convocava dois génios ibéricos, Miguel Cervantes e Miguel de Unamuno - mestres deste outro filho da grande Ibéria e clarões nas trevas em seu redor desde o golpe militar de 1926 - e a torga, a erica lusitanica, urze e flor do monte cor de vinho que deita raizes fortes sob a aridez da rocha." (Ver site $A$ Voz do Chão, Miguel Torga, da Biblioteca Nacional de Portugal em http://purl.pt/13860/1/miguel-torga.html). Manteve-se a grafia portuguesa do site e assim será feito ao longo do artigo em relação aos textos originais portugueses.

4 Planta nativa de Portugal Continental, ocorrendo no noroeste, interior Norte, centro e sul, incluindo Serra da Estrela, nos brejos e margens de ribeiros, nos solos ácidos. Informações recolhidas em https://naturdata.com/especie/Erica-lusitanica/38732/0/. Acesso em 02 de setembro de 2020. Ver também nfusoescomhistoria.pt/conheca-3-coisas-que-desconhecia-sobre-a-urze-vermelha/. Acesso em 02 de setembro de 2020 . 
em sua fragilidade e pequenez, bicho da terra tão pequeno ${ }^{5}$. Escritor e médico, rigoroso, solitário, agreste, como muitos o descreveram, Torga legou-nos uma obra extensa que reflete muito bem sua exigência ética, seu compromisso com a vida e o amor silencioso mas profundo por sua terra, seja o país em que nasceu (Portugal de 1907), seja a pequena vila transmontana na qual seus pais viveram até a morte, espaço fundamental na formação interior do homem Adolfo Correia Rocha, que sempre a revisitou ao longo de sua vida até o seu falecimento, em 1995. A relação com essa geografia nativa, com as paisagens inscritas em seus olhos, mente e obras, refletem um pensamento-paisagem fundamental para compreender o compromisso desse escritor com o mundo que o viu nascer e que transladou para suas obras, com observação atenta de uma vida rural em um tempo português sem liberdade e com uma ética biográfica e autoral manifestada constantemente em seus atos e em suas palavras.

Antes, porém, de examinar algumas passagens da obra torguiana, mais precisamente, de oito volumes de seu Diário $^{6}$, para analisar como a relação com a paisagem ${ }^{7}$ de origem ganha relevância imaginante na elaboração de sua obra, consideramos necessário enfatizar a importância de pensar a paisagem como elemento constituinte da escrita de certos autores. Os estudos de paisagem em nossa contemporaneidade assumiram uma dimensão muito ampla e diversificada na proporção do enfrentamento de um urbanismo galopante que toma todos os países e gera, pelas condições capitalistas e globalizantes, a massificação de tudo na vida cotidiana. Se a paisagem sempre esteve presente na arte ocidental, inicialmente, como composição decorativa, foi, no correr dos séculos, ganhando força hermenêutica e constituindo-se, sobretudo na viragem cultural dos anos 70 do século $\mathrm{XX}$, uma questão fundamental de debate nas ciências humanas e nos estudos estéticos. Em nosso campo de

\footnotetext{
5Os versos camonianos que encerram o canto 1 de Os Lusíadas bem poderiam servir de epígrafe a este artigo por dialogarem muito bem com a escrita torguiana, profundamente humana e responsável com o estar no mundo. "Onde pode acolher-se um fraco humano, / Onde terá segura a curta vida, / Que não se arme e se indigne o Céu sereno / Contra um bicho da terra tão pequeno?" (Lus, I, 106: 5-8)

6Esse Diário é constituído de 16 volumes publicados progressivamente, de 1941 e 1994. Em suas páginas, ao lado das memórias domésticas e profissionais cotidianas, registram-se poemas, crônicas, breves contos, reflexões críticas, literárias e políticas. Para este artigo, trabalhamos com a edição portuguesa do Círculo de Leitores (2001), com licença editorial de Publicações Dom Quixote, que reúne o total de volumes originais em quatro volumes somente. Tal edição "tomou por base o texto da $1^{a}$ edição integral (Coimbra, 1995) preparada pelo próprio Autor". Todas as citações feitas neste artigo indicarão, portanto, a edição de 2001, com paginação contínua para Diário (volumes I a IV, p.17 a 421) e Diário (volumes V a VIII, p. 422 a 830). Na transcrição de passagens torguianas, conservamos a grafia portuguesa original e fazemos a indicação de data.

7Consulte-se também o artigo "A paisagem no Diário de Miguel Torga" (CARVALHO, 2013) sobre a noção de paisagem nos volumes de Diário, de Miguel Torga. Disponível em https://repositorio.ul.pt/bitstream/10451/24712/1/Tiago\%20163-181.pdf . Acessado em 02/09/2020.
} 
estudos literários comparados, por exemplo, temos acompanhado muito de perto o pensamento teórico de Michel $\mathrm{Collot}^{8}$ que, desde os anos 80, vem indagando sobre esse tema e publicando obras seminais para a discussão e compreensão paisagística na literatura. Por sua vez, Collot, de forma recorrente, lembra seu mestre Jean-Pierre Richard, como figura cimeira de estudo da paisagem pela linha da fenomenologia hermenêutica, sobretudo com seu livro Pages paysages (1984), o qual marca uma perspectiva fundamental para a constituição da crítica temática. Na primeira edição brasileira de reunião de estudos de Michel Collot intitulada Poética e Filosofia da Paisagem (2013), o ensaísta francês defende a importância do pensamento de Jean Pierre Richard para compreender "o que é uma paisagem literária". Destaca de Richard três definições do que seria, para ele, paisagem em obras literárias:

[...] Em primeiro lugar, o conjunto dos elementos sensíveis que constituem a matéria e como o terreno de sua experiência criativa. [...] A paisagem de um autor talvez também seja esse mesmo autor tal como se oferece completamente a nós, como sujeito e como objeto de sua própria escrita. [...] É, em suma, esse espaço de sentido e de linguagem do qual a crítica se esforça por mostrar a coerência única, por determinar o sistema. (2013, p. 55)

A partir dos pressupostos analíticos de Richard ${ }^{9}$ em todo o seu trabalho de leitura das paisagens configuradas em linguagem por autores franceses como Baudelaire, Corbière, Laforgue, Flaubert, Saint-John Perse, Gracq e Ponge, entre outros, conclui Collot: "É a conjunção de uma percepção singular do mundo, de uma organização literal, de uma impressão de leitura e de sua elaboração crítica que produz o que se poderia chamar de um “efeito-paisagem”. (2013, p.55)

O próprio Collot, em seu livro La Pensée-Paysage (2011), discute a importância desse pensamento na constituição da escrita de poetas e prosadores. Sua perspectiva de

8Coordenamos a equipe de tradução do livro organizado por esse autor francês para o público brasileiro sob o título de Poética e filosofia da paisagem. Oficina Raquel: Rio de Janeiro, 2013.

9Em sua obra intitulada Pages Paysages (Microlectures II), de 1984, Richard, em seu “Avant-propos”, explica: "Pages, paysages: les divers essais critiques ici rassemblés obéissent, comme ceux qui les ont précédés, à un désir double. On y tente une lecture qui se fonderait à la fois sur l'essence verbale des oeuvres littéraires (ce qui les constitue en pages), et sur les formes, thématico-pulsionnelles, par où s'y manifeste un univers singulier (ce qui les organise en paysages). Ajoutons que, dans leurs dispositifs littéraux, leurs reliefs ou pentes d'écriture, les pages peuvent se contempler comme des paysages; et les paysages à leur tour, à travers leurs configurations sensorielles, leur logique, leur ordre secret, se comprendre, se lire comme autant de pages." (1984, p.7). 
trabalho muito fortemente ligada à fenomenologia, sobretudo a de Merleau-Ponty (2011), defende a paisagem como um espaço transacional, "si le paysage donne à penser, la pensée se déploie comme paysage" ${ }^{10}$ (p. 36). Como também afirma na tradução brasileira já referida de alguns de seus estudos:

\begin{abstract}
A paisagem aparece, assim, como uma manifestação exemplar da multidimensionalidade dos fenômenos humanos e sociais, de interdependência do tempo e do espaço e da interação da natureza e da cultura, do econômico e do simbólico, do indivíduo e da sociedade. A paisagem nos fornece um modelo para pensar a complexidade de uma realidade que convida a articular os aportes das diferentes ciências do homem e da sociedade (2013, p.15).
\end{abstract}

Esse recorte contextual teórico-analítico permite aproximarmo-nos da obra do escritor português Miguel Torga para chamar atenção exatamente para a figuração da paisagem em sua escrita como matéria metaliterária. É pensando nesse "pensamentopaisagem" que desejamos enfatizar em sua obra ficcional uma estrutura paisagística que lhe dá não apenas conteúdo determinado (o horizonte rural de um Portugal interior das primeiras décadas do século XX) mas sobretudo uma linguagem literária marcada pela experiência da terra e do seu trabalho, pelo agreste, pelo sentimento de habitação de um mundo agrário marcado pela escassez, miséria mas também por uma vivência humana resiliente e forte. Como afirma Collot (2013), “A paisagem de um escritor não se reduz a qualquer um dos lugares onde ele viveu, viajou ou trabalhou. Ela não é nem mesmo uma composição mais ou menos sutil desses referentes geográficos e biográficos, mas uma constelação original de significados produzidos pela escrita" (p.58).

Neste artigo não vamos tratar exatamente dos contos ou da poesia torguiana que já conta com uma fortuna crítica longa, mas examinar uma outra produção bastante instigante desse autor, que reúne não só sua visão pessoal da vida cotidiana e coletiva, como também sua visão estética. Tratamos de Diário (2001) que cobre várias décadas de seu percurso até 1994, um ano antes de seu falecimento. São exatos 16 volumes originais reunidos, na edição do Círculo do Livro, em 4 volumes a constituírem um testemunho quase inesgotável das linhas de atenção de seu trabalho. Entretanto, neste artigo, analisamos somente os diários (de I a VIII, volumes 1 e 2, da edição de 2001) que cobrem o período de 1932 a 1959, anos

10“Se a paisagem provoca o pensar, o pensamento se desdobra como paisagem”. Tradução nossa. 
em que produziu a maior parte de sua obra poética e narrativa, para evidenciar o entrelaçar da paisagem vivida com a paisagem literária. Esse entrelaçamento configura o que nomeamos como o pensamento-paisagem torguiano, o que nos permite compreender sua percepção de mundo como homem português a viver num século tão conturbado como o vinte.

No conjunto dos diários, claro está que domina, espacialmente, a cidade de Coimbra, onde o escritor, que se formou médico, estudou e exerceu a profissão como "médico especialista ouvido, nariz e garganta" ${ }^{11}$. São referenciadas igualmente algumas cidades à volta que frequentou por ofício e todas as cidades que visitou em Portugal e no estrangeiro, por missão profissional, literária ou turística. Entre tantos espaços sobre os quais comenta ou anota algo em seu diário, há uma geografia íntima que se estende como um fio de memória e de existência humana, precisamente a vila de nascimento, S. Martinho de Anta, antiga freguesia do Concelho de Sabrosa, contemporaneamente, desde 1999, com estatuto de Vila, na região de Trás-os-Montes. Ainda que dela se afaste, em definitivo, para morar em Coimbra, ficou no homem uma relação profunda com aquela natureza e matéria humana que ressoarão em suas páginas, transformadas em imagens e reconfiguradas numa estrutura paisagística que caracterizará sua escrita ao longo da vida. O próprio escritor afirma: "S. Martinho foi o lugar donde. Coimbra o centro desse mundo misterioso e apaixonante que de lá perspectivei”. (Torga, 1993, p. 22).

A vila de nascimento é comentada em seus diários como espaço de autoconhecimento e sedimentação de sua história interior. Pelo que vai transmitindo a seu respeito, podemos destacar visões, afirmações e experiências que são o substrato de sua escrita literária, prosa e verso, mas sobretudo de seus contos, produção em que Torga alcançou a excelência. É necessário ainda lembrar que o escritor publicou em 1941 a conferência Um reino maravilhoso (Trás-os-Montes) e, em 1950, Portugal, uma geografia literária cheia de afeto por seu país tão variado em paisagens. Nesse livro, republicou a conferência.

A autoridade emana da força interior que cada qual traz do berço. Dum berço que oficialmente vai de Vila Real a Montalegre, de Montalegre a Chaves, de Chaves a Vinhais [...] da Barca à Régua e da Régua novamente a Vila Real, mas a que pertence [...] toda a vertente esquerda do Doiro até aos contrafortes do Montemuro, carne administrativamente enxertada num

11Conforme placa do consultório. Ver em http://purl.pt/13860/1/miguel-torga.htm. Acessado em 02 de setembro de 2020. 
corpo alheio [...] Um mundo! Um nunca acabar de terra grossa, fragosa, bravia, que tanto se levanta a pino num ímpeto de subir ao céu, como se afunda nuns abismos de angústia, não se sabe por que telúrica contrição. Terra-Quente e Terra-Fria. Léguas e léguas de chão raivoso, contorcido, queimado por um sol de fogo ou por um frio de neve. Serras sobrepostas a serras. Montanhas paralelas a montanhas (Torga, 1996, p. 31-32).

Mas voltemos ao Diário. Nesse diálogo consigo, ao longo de tantos anos ${ }^{12}$, Torga vai demonstrando sua pertença a essa natureza e como está ela entranhada em sua formação mental e na sua criação literária. No Diário (2001), a primeira entrada sobre S. Martinho de Anta, datada de 3 de março de 1934, aponta a insatisfação torguiana de não estar numa cidade maior com seus eléctricos e livrarias, mas, dois dias depois, a reflexão é sobre a própria ambiguidade de sua individualidade, pois, de um lado, sente a íntima comunhão com essa terra: "A linguagem que o meu sangue entende - é esta. [....] O chão que os meus pés sabem pisar - é este" (p.19), de outro, compreende-se transformado pela experiência urbana, pela vida que tem em Coimbra. "Pareço uma destas árvores que se transplantam, que têm má saúde no país novo, mas que morrem se voltam à terra natal.” (p.19). No dia seguinte a essa anotação no diário (6 de Março de 1934), registra um poema intitulado "Paisagem", em que se irmanam natureza e corpo, na intimidade de sentimentos.

\footnotetext{
Hirtos, os montes velam

O cadáver gelado do meu sonho.

Num desespero íntima, contido,

Que seca na raiz toda a verdura,

Velam seu corpo astral, caído

Numa vala sem fundo de amargura.

(p.19)
}

Entretanto, é importante notar como suas reflexões a respeito de sua existência, pensamento e obra se valem recorrentemente de imagens camponesas ligadas à terra de origem. Indica aí sua raiz, ser como árvore, cercado por montes. Em abril de 1938, exclama meio a sério, meio irônico: "Esse Trás-os Montes da minha alma! Atravessa-se o Marão, e entra-se logo no paraíso" (p. 48). Se o escritor sente falta da cidade de Coimbra, onde vive e há outras possibilidades culturais, reconhece que a sua literatura é produto dessa paisagem agreste que se entranhou em seu corpo, que faz parte de sua memória afetiva, de seu

12Os 16 volumes de Diário, em sua primeira edição, foram publicados respectivamente em 1941, 1943, 1946, 1949, 1951, 1953, 1956, 1959, 1964, 1968, 1973, 1977, 1983, 1987, 1990 e 1994. O autor faleceu em $17 / 01 / 1995$. 
imaginário. Em 22 de abril de 1938, já se preparando para retornar a Coimbra, escreve: "Volto amanhã. Uma semana. É pouco. Precisava de bem mais. Mas assim mesmo já levo terra nas unhas que dava para a Central inteira. Preciso disto. Necessito de vir enxertar de quando em quando a debilidade nesta cepa.” (p.49-50). A relação com essa paisagem de origem não é bucólica ou romântica, mas crítica, dando-lhe consciência aguda da situação social e política do Portugal de seu tempo, mas ainda da condição humana num mundo sem justiça. "Eu trouxe de lá angústia, tortura, crítica negativa a tudo. A razão não a sei. Talvez sina, talvez desilusão crónica que se me colou à pele ao nascer...” (p.64), escreve em Coimbra, a 10 de Mario de 1939.

No seu ideário literário, o humano tem lugar nuclear, com suas pequenas alegrias, mas sobretudo suas dores, desilusões e mortalidade. Os homens se aproximam dos animais, na sua energia inicial, inquietude, busca de sobrevivência, mas ambos perdem a força, desaparecem. Já a natureza vegetal e a terra se renovam continuamente, estáticas e impassíveis. "Mil vezes então a continuidade de um vegetal. Mil vezes este nunca sorrir, este nunca saltar, este nascer e morrer com a mesma cara, este olhar todas as fases da vida com a mesma seriedade e a mesma compostura" (p.87). Torga invoca continuamente um pensamento-paisagem que dirige sua identidade e sua escrita: "Eu gosto da paisagem. Mas amo-a duma maneira casta, comovida, sem poder macular a sua intimidade em descrições a vintém por palavra. Chego a uma terra e não resisto: tenho de me meter pelos campos fora, pelas serras, pelos montes, saber das culturas, beber o vinho e provar o pão" (p. 144). Numa conversa com um camponês, queixoso da mulher e das filhas, ouve do homem a argumentação: “As árvores e as pessoas é do berço que mostram a condição. Sou enxertador. Pois ainda não vi de mau pé fazer boa fruteira! A gente bem põe um garfo de qualidade, bem põe...É escusado; a natureza não quer, não quer mesmo. A coisa tem de vir de baixo, do fundo..." (p.145) O contato com a terra e os camponeses, que Torga ouve atentamente e compreende, atravessa seu próprio entendimento da escrita literária. Sua obra persegue determinados temas como o telúrico, a força da natureza, a ânsia de vida em oposição à fraqueza humana, a íntima relação entre um homem e sua terra, a ideia de raiz, de luta contínua pela sobrevivência e consciência crítica de uma engrenagem social desigual e desumanizadora.

Em 1942, a 26 de outubro, estando em Açor, Serra da Lousã, expõe a relação reflexiva com a paisagem que se apresenta em sua obra, não como elemento a ser descrito 
compondo moldura para o narrativo, mas como um pensamento de estar no mundo, um modo de habitá-lo que se apresenta no corpo do homem e em seu corpo de escrita:

\begin{abstract}
Aqui estou, no alto desta serra ondulada, sentado, a contemplar um largo horizonte $[\ldots]$. De resto, faz parte do meu ritual subir aos altos, sentir a voluptuosidade da fadiga, como diz Unamuno e depois olhar. Devo à paisagem as poucas alegrias que tive no mundo. Os homens só me deram tristezas. Ou eu nunca os entendi, ou eles nunca me entenderam.[...]. A terra, com os seus vestidos e as suas pregas, essa foi sempre generosa. É claro que nunca um panorama me interessou como gargarejo. É mesmo um favor que peço ao destino: que me poupe à degradação das habituais paneladas de prosa, a descrever de cor caminhos e florestas. As dobras e as cores do chão onde firmo os pés foram sempre no meu espírito coisas sagradas e íntimas como o amor. Falar duma encosta coberta de neve sem ter a alma branca também, retratar uma folha sem tremer como ela, olhar um abismo sem fundura nos olhos, é para mim o mesmo que gostar sem língua, ou cantar sem voz. Vivo a natureza integrado nela. De tal modo, que chego a sentir-me, em certas ocasiões, pedra, orvalho, flor ou nevoeiro. Nenhum outro espectáculo me dá semelhante plenitude e cria no meu espírito um sentido tão acabado do perfeito e do eterno. [...] Eu declaro aqui a estas fundas e agrestes rugas de Portugal que nunca vi nada mais puro, mais gracioso, mais belo, do que um tufo de relva que fui encontrar um dia no alto das penedias da Calcedónia, no Gerês. [...]" (p.156-157)
\end{abstract}

Em 23 de março de 1943, Torga escreve um poema intitulado "Condição":

É de pedra esta triste melodia

Onde rasgo o volume do meu canto;

É dum granito negro que vigia

A pureza maciça do meu pranto.

Dura,

Solitária e cerrada,

Tem beleza e ternura,

Mas é fraga pisada...

Fraga velha e batida

Pela dor de almocreves e carreiros,

Só nela eu posso eternizar a vida,

Minha e dos companheiros...

(p. 195).

E mais de um ano depois (23 de maio de 1944), anota outro poema agora intitulado "Marão", em que o sujeito lírico, mais uma vez, é constituído dos elementos naturais que mais cita: serra, pedra, raiz. Esses termos marcam sua pertença a um mundo, a um estado severo e rude que, no entanto, não está afastado da ternura e da beleza. 
Serra, seio de pedra

Onde mamei a infância.

Amor de mãe, que medra

Quando medra a distância.

Dura severidade

Tapetada de acenos

Às ilusões da idade

$\mathrm{E}$ aos deslizes pequenos.

Velha raiz segura

À universal certeza

De um gesto de ternura

E um pouco de beleza.

(p. 251)

Já em 21 de Março de 1943, reflete que se deveria fazer "do homem um dos elementos fundamentais da geografia" (p. 195). Note-se a compreensão torguiana, bem antes da afirmação da geografia humanista ou cultural, a respeito da importância da relação entre homem e o espaço vivido. Argumenta o escritor: "O indivíduo - o enraizado, claro está exprime, queira ou não queira, a própria alma do chão que o viu nascer. No seu carácter, na luz dos seus olhos, na sua fala (nesta, então, só um cego é que não vê!), estão a geologia inteira de uma região" (p. 196) Mas seu amigo geógrafo "argumenta-me com razões de método, chama a isto uma ideia poética, e fala no sarilho científico que seria semelhante geografia psicológica. Diante de tais argumentos, calo-me, vencido mas não convencido" (p. 197).

O escritor não deixa de lado, em suas anotações, o contraste entre a paisagem geográfica e a paisagem humana: de um lado, sente a beleza e a força; de outro, a desgraça e a miséria. Tal contraste aliás atravessa seus livros Bichos, Contos da Montanha e Novos Contos da Montanha, publicados em 1940, 1941 e 1944, respectivamente. Anota em 08 de junho de 1946, estando em S. Martinho de Anta: 
As raízes começam a secar. Minha Mãe está no fim, meu Pai ensurdece, a beleza das giestas floridas não resiste ao espectáculo lancinante de ver crianças famintas a pastar ervas como animais. Só o Marão, ao longe, conserva a majestade de sempre e a sua pureza habitual de deus. Mas nem a olhá-lo pude esquecer por muito tempo a miséria desta gente. Uma fibra humana que me repuxa a alma cada vez com mais força desenhou-me cruamente naquele azul de ilusão e de evasão a legenda que conheço desde menino:

—Bem grande é o Marão, e não dá palha nem grão (p. 307).

O escritor é completamente atento à geografia portuguesa como ao patrimônio cultural material e imaterial que conhece como seu espaço vivido ou experimentado. Defende a ligação profunda entre essa geografia percebida e a criação artística, notadamente a poesia. Estando no Gerês, a 9 de agosto de 1950, anota, "Quanto mais percorro o país, mais me convenço de que ainda são os poetas que melhor sabem exprimir a nossa realidade telúrica e humana" (p. 481).

Em 23 de dezembro de 1950, de volta a S.Martinho de Anta, reafirma a imagética que o identifica ao longo de toda sua obra - raiz - e sua luta constante com a escrita que deseja justa e fiel a seu horizonte de ser.

Cá estou de novo plantado no centro da minha paisagem, como uma macieira no centro da sua leira. Dum lado a escadaria que leva ao Doiro, e do outro o icebergue do Marão. O ar fresco da noite corta-me o rosto, e pelas raízes entra-me a seiva duma terra que é fecunda desde o dia da criação. E, contudo, não tenho nada de novo que dizer, não me ocorre uma frase que seja um fruto desta levedação. A paisagem, da mesma maneira que a quadra que passa, é ritual. E tudo o que é ritual só é formulável uma vez (p.512).

Cada retorno à terra de seus pais, ao longo dos anos, é um retorno a si próprio como pensamento-paisagem. Reencontra a matéria de que é feita sua escrita, evidencia a imagem de mundo e do eu como "uma construção literária, indissociável das estruturas semânticas e formais da obra", como diz Collot em diálogo com Richard (Collot, 2013, p.55). O poema anotado no Natal de 1951 nomeia-se "Regresso"13 com versos que figuram o poeta

13 Regresso às fragas de onde me roubaram. /Ah! Minha serra, minha dura infância! / Como os rijos carvalhos me acenaram, / mal eu surgi, cansado, na distância! // Cantava cada fonte à sua porta: / O poeta voltou! / Atrás ia ficando a terra morta / Dos versos que o desterro esfarelou. // Depois o céu abriu-se num sorriso, / E eu deitei-me no colo dos penedos / A contar aventuras e segredos / Aos deuses do meu velho paraíso. 
reconhecido pela serra, pelo "rijos carvalhos", acolhido no "colo dos penedos", "deuses do meu velho paraíso" (p. 555).

Dois anos depois, em 1 de janeiro de 1953, de novo na sua aldeia, reafirma o que podemos dizer ser a sua ética pessoal herdada do pai, que o guia também na sua compreensão literária:

[...]no fundo agradeço a meu Pai a sua fidelidade à terra, ao estrume, à pobreza. Há nessa obstinada humildade uma incorruptível nobreza de condição. A palavra correcta, a barba feita, a braguilha abotoada são perfeições que um literato pode desejar, mas que um honrado cavador necessariamente dispensa. Como há-de ele aparecer-nos de mãos escaroladas, se vem justamente de apanhar com elas a bosta que uma junta de bois deixou ao passar - adubo que seria uma dor de alma perder? O convívio diário com camponeses de ficção - os de Lawrence, que lêem Platão, ou mesmo os de Eça, que são caseiros de Jacinto - afasta-nos da compreensão duma realidade humana que só com óculos cor-de-rosa pode ser mistificada. Ora o velhote nem se ilude, nem quer iludir. E, diante do rei que seja, apresenta-se tal como é: uma evidência natural, só polida por dentro - e nisso delicada, solidária, franca e até espirituosa.

Com pouco tempo disponível, o camponês vai direto ao essencial. E ergue a sua personalidade como ergue as videiras: o suficiente apenas para que a vida dê frutos. (p.600).

Ainda referindo-se ao pai, em 16 de agosto de 1955, estando no Gerês, reflete:

A terra tem um senão: a mudez. E o poeta é um homem de perguntas. Desde que me conheço que me dilacera o cilício de a interrogar sem esperança. Ora o chão transmontano fala-me pela boca de meu pai. Na sua dignidade de cavador cumprido, de príncipe que depôs a enxada sem abdicar dela, o velho como que atingiu o recolhimento sábio e tutelar necessário aos oráculos do cósmico. Num rifão, num gesto, numa atitude, responde-me às perguntas mais perturbadoras, e é o próprio telúrico que me responde. A serena confiança que irradia, a paz com que espera a morte, a força com que nivela os homens no estalão natural, a exemplaridade polarizadora da sua inteireza, iluminam-me o entendimento e fazem-me compreender as courelas que lavrou e as pedras que os seus pés calcaram. Por isso, depois de cada visita que faço ao duro berço que me viu nascer, parece que tenho vendas nos olhos e só vejo por dentro. A vida fica baça à minha volta, e todo eu me concentro na demorada contemplação da íntima claridade. (p. 725-726).

Torga é daqueles escritores portugueses sobre os quais podemos dizer que são escritores geógrafos, porque a paisagem, em suas obras, não é meramente um elemento compositivo mas a constituição de uma estrutura profunda de sentido que dá à escrita sua 
humanidade e sua força hermenêutica. Há uma grafia permeada de terra, de raízes, montes e pedras que transferem para as palavras fidelidade ao humano, sensibilidade vital, rigor formal e escuta atenta ao mundo. Por isso, em 6 de abril de 1955, escreve, tendo olhos nas fragas de S. Martinho de Anta:

Conseguir na prosa a dignidade e a força descarnada destas fragas, e nos versos a pureza e a largueza dos horizontes que delas se descortinam, é o instintivo propósito da minha ambição de artista. Mas, desgraçadamente, sei que as palavras não resistem ao pico dum pedreiro teimoso como o vento, ou à inquietação que as distenda até ao infinito.

Quando o desbaste tenta chegar ao sabugo, ou a imaginação as projecta para além de certos limites, esfarelam-se no bico da pena ou esfumam-se no binóculo dos olhos (p. 715).

Essa dignidade e força descarnada estão presentes nas páginas torguianas. O escritor nunca deixou de lado o compromisso com seu tempo e com sua terra portuguesa, espelhando em sua prosa e poesia a situação de miséria, ignorância e falta de liberdade que marcava as aldeias portuguesas até os anos 70 do século passado. Com edições de autor, com independência de voz e atos, sua escrita articulou terra, homem e palavras, construindo uma obra humanista e comprometida com o presente. A consciência desse compromisso já apontara em resposta a um inquérito do Journal des Poètes, com entrada no Diário, a 16 de abril de 1952:

O poeta é sempre do seu tempo, de uma maneira positiva ou negativa. Positiva, se é capaz de intuir o íntimo sentido da sua época e lhe encontra a expressão poética presente e a ressonância poética futura; negativa, se não passa de um doirador obtuso do que nessa mesma época é cisco circunstancial. [...] De resto, como poderia o poeta não ser do seu tempo, se ele é sempre a mais alta consciência de um tempo? O poeta não é uma abstração. É um ser real, que existe no real. Por isso, não poderá evadir-se da vida, que o marca e é marcado por ele. A fundura dessas mútuas cicatrizes é que varia (p. 562).

Se foi nessa terra da infância e mocidade, que se tornou consciente do "meu destino de artista, bafejado por não sei que estimulante vento do espírito", como anota em 1 de outubro de 1957, a respeito do Monte de S. Domingos em S. Martinho de Anta (p.772), é sempre retornando a essa geografia íntima, inscrita em suas obras, que o escritor reconhece 
seu mundo e seu sentido, como se lê no encerramento do Diário VIII, em 22 de novembro de 1959:

Paro um momento no meio das encostas a tomar fôlego, e ponho-me logo a magicar na significação destas visitas, que obedecem sempre ao mesmo ritual: à vinda, do alto do Marão, cumprimento, apenas topográfica e sentimentalmente, a Senhora da Azinheira; à ida, recebo em Sabrosa, das mãos vizinhas de Fernão de Magalhães, passaporte para todas as inquietações; no intervalo, inventario as fragas nativas. Três tempos, com três sentidos escalonados: o do céu perdido, o do ninho limitado e o da terra inteira abraçada... (p.829)

\section{Referências}

CARVAlHO, Tiago Mesquita. A paisagem no Diário de Miguel Torga. Philosophica, 42, Lisboa, 2013, pp. 163-181.

COLLOT, Michel. La pensée-paysage. Philosophie, Arts, Littérature. Paris: Actes Sud /ENSP, 2011.

Poética e filosofia da paisagem. Rio de Janeiro: Oficina Raquel, 2013.

SOUSA, Carlos Mendes de. Cartas para Torga. In Jornal de Letras, Artes e Ideias, Lisboa, 15 a 28 de janeiro de 2020, p.12.

RICHARD, Jean-Pierre. Pages Paysages. Microlectures II. Paris: Éditions du Seuil, 1984.

TORGA, Miguel. Diário (volumes I a IV e V a VIII). Lisboa: Círculo de Leitores, 2001.2v. Diário XVI. Ed do Autor, 1993.

Portugal. Rio de Janeiro: Nova Fronteira, 1996.

Artigo recebido em: 15.09 .2020

Artigo aceito para publicar em: 22.10.2020 